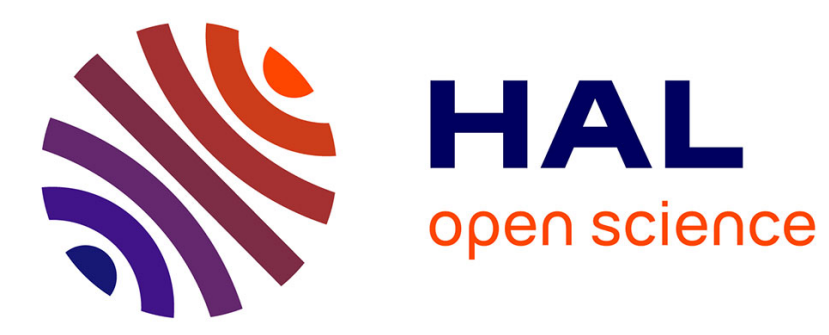

\title{
Experiments and modelling of the compressive behaviour of two $\mathrm{SiC}$ ceramics
}

Pascal Forquin, Christophe Denoual, C.E. Cottenot, François Hild

\section{To cite this version:}

Pascal Forquin, Christophe Denoual, C.E. Cottenot, François Hild. Experiments and modelling of the compressive behaviour of two SiC ceramics. Mechanics of Materials, 2003, 35 (10), pp.987-1002. 10.1016/S0167-6636(02)00321-6 . hal-02344988

\section{HAL Id: hal-02344988 \\ https://hal.science/hal-02344988}

Submitted on 4 Nov 2019

HAL is a multi-disciplinary open access archive for the deposit and dissemination of scientific research documents, whether they are published or not. The documents may come from teaching and research institutions in France or abroad, or from public or private research centers.
L'archive ouverte pluridisciplinaire HAL, est destinée au dépôt et à la diffusion de documents scientifiques de niveau recherche, publiés ou non, émanant des établissements d'enseignement et de recherche français ou étrangers, des laboratoires publics ou privés. 


\title{
Experiments and modelling of the compressive behaviour of two SiC ceramics
}

\author{
P. Forquin ${ }^{\text {a }}$, C. Denoual ${ }^{\mathrm{a}, 1}$, C.E. Cottenot ${ }^{\mathrm{a}}, \mathrm{F}_{\text {. Hild }}^{\mathrm{b}, *}$ \\ ${ }^{a}$ DGA/CTA, Département Matériaux, Surfaces, Protection, 16 bis avenue Prieur de la Côte dor, F-94114 Arcueil Cedex, France \\ ${ }^{\mathrm{b}}$ Laboratoire de Mecanique et Technologie, Cachan, ENS de Cachan/CNRS/University Paris 6, 61 avenue du Président Wilson, \\ F-94235 Cachan Cedex, France
}

\begin{abstract}
To analyse compressive damage generated during a high-energy impact on ceramic targets, quasi-static uniaxial compressive tests are performed on two silicon carbide grades. These two grades ( $\mathrm{S}-\mathrm{SiC}$ and $\mathrm{SiC}-\mathrm{B}$ ) are characterised by different processing routes, porosity levels and tensile strengths. A new specimen geometry is proposed. Post-mortem studies carried out on a specimen embedded before compression allow us to visualise the final damage pattern. A highspeed camera is also used. Photographs of cracking and debris ejection are obtained a few microseconds after the inception of failure. In addition, thin strips are cut out of $\mathrm{S}-\mathrm{SiC}$ and $\mathrm{SiC}-\mathrm{B}$ specimens loaded and unloaded before failure. An anisotropic damage model is introduced to explain the failure scenario. A first numerical simulation substantiates the hypothesis of failure caused by tensile stresses induced by a roughness defect. A second analysis using the mesh of a half specimen matches the different observations obtained from post-mortem studies and with the high-speed camera.
\end{abstract}

Keywords: Damage model; Dynamic fragmentation; Probabilistic approach; Roughness; Silicon carbide; Uniaxial compression; Weibull model

\section{Introduction}

For few decades, steel armours of military vehicles were thought to be too heavy. Therefore lighter solutions were developed to increase their mobility. Among the armour concepts to resist perforation by projectiles of small and medium calibre, the bilayered geometry is one of the most promising solutions (Cottenot et al., 1998) that saves about $30 \%$ in weight in comparison with monolithic-steel armours. This assembly comprises:

- the front layer: a hard material (e.g., ceramic) that aims at breaking or blunting the projectile and spreading out the energy of impact by forming a cone-shaped cracking zone, 
- the back layer: a material that ensures the structural integrity (e.g., steel, aluminium alloy or composite). This material aims at absorbing the impact energy.

The hardness and the high strength in compression as well as the low density of ceramics make them particularly attractive as front layer materials, even though they fragment during impact. When a projectile hits a ceramic armour, a compressive wave propagates in the material with a very high velocity. One microsecond after impact, the radial displacement of the material creates an orthoradial tension inducing microcracking that can be described by an anisotropic damage model (Denoual and Hild, 1998). When the impact speed is greater than $700 \mathrm{~m} / \mathrm{s}$, compressive damage may have an influence on the projectile penetration capability and on the location of the fragmented zone. Therefore, the study of damage in compression is also needed.

To characterise the dynamic behaviour of ceramic materials, several types of tests were devised. Plate impact experiments are among the most used set-ups and allow the generation of a uniaxial strain history for strain rates $|\dot{\varepsilon}|>10^{5} \mathrm{~s}^{-1}$. The material behaves first elastically and then nonlinearly beyond the Hugoniot Elastic Limit (HEL). The HEL may represent the macroscopic manifestation of microplasticity (e.g., dislocations, twinning (Cosculluela, 1992)) or damage (e.g., microcracking (Yaziv, 1985)). Table 1 summarises the values reported by different authors on two SiC grades that will be studied herein. The value $\sigma_{\mathrm{HEL}}$ of the HEL is given as well as the corresponding yield stress $\sigma_{\mathrm{y}}$ for a Tresca or Von Mises criterion

$\sigma_{\mathrm{y}}=\frac{1-2 v}{1-v} \sigma_{\mathrm{HEL}}$

where $v$ is the Poisson's ratio of the undamaged material.

Other tests are used to evaluate the compressive behaviour of ceramics. In particular, the spherical expansion cavity experiment consists in detonating a hemispherical cavity containing an explosive on a half space of the ceramic material. This experiment has the advantage of generating a loading well known and representative of a ballistic impact. This test was used by Cosculluela (1992) with alumina ceramics, by Tranchet (1994) with

Table 1

Hugoniot elastic limit, $\sigma_{\mathrm{HEL}}$, yield stress, $\sigma_{\mathrm{y}}$, and compressive failure stress, $\sigma_{\mathrm{comp}}$ for different $\mathrm{SiC}$ grades (QS: quasi-static experiment, SHPB: split Hopkinson pressure bar)

\begin{tabular}{llll}
\hline Type of test and SiC grade & Reference & $\sigma_{\mathrm{HEL}}(\mathrm{GPa})$ & $\sigma_{\mathrm{y}}(\mathrm{GPa})$ \\
\hline Plate impact S-SiC & Cagnoux et al. (1987) & 13.5 & 10.9 \\
& Bourne et al. (1997) & 13.5 & 10.9 \\
Plate impact SiC-B & Kipp and Grady (1990) & $14.8-15.3$ & $12.0-12.4$ \\
& Feng et al. (1997) & 11.5 & 12.3 \\
& Bourne et al. (1997) & 15.7 \\
QS compression $\alpha-\mathrm{SiC}$ & & $\sigma_{\text {comp }}(\mathrm{GPa})$ & -4.0 \\
& Lankford (1981) & -4.55 \\
QS compression SiC-HP & Dunlay et al. (1989) & -6.92 \\
QS compression S-SiC & Dunlay et al. (1989) & Bourne et al. (1997) & -5.21 \\
QS compression SiC-B & This work & -6.7 \\
SHPB compression S-SiC & Bourne et al. (1997) & -5.15 \\
SHPB compression SiC-B & This work & -5.8 \\
\hline
\end{tabular}


quartzite and by Malaise (1999) with S-SiC ceramics.

Uniaxial compression tests are quite difficult to perform but they show some advantages. Contrary to a confined compression test, the lower hydrostatic pressure of a uniaxial compression makes easier the activation of compressive damage (e.g., microplasticity, microcracking). Moreover, one may wonder whether the Weibull moduli obtained from flexural quasi-static tests are the same as those obtained under quasi-static as well as dynamic compressive loadings. Consequently, the level and scatter of the failure stress in quasi-static uniaxial compressive tests are key elements to determine.

This paper is devoted to the analysis of results of compressive experiments on two silicon carbide grades. The microstructural and failure features are presented in the first part. The second part is devoted to uniaxial compression tests used for ceramic materials. The set-up used with $\mathrm{S}-\mathrm{SiC}$ and SiC-B ceramics and all the observations carried out during and after the experiments are discussed. In the last part, numerical simulations attempt to explain the different experimental observations.

\section{Properties of two silicon carbide grades}

Two silicon carbide grades are examined. The first one, called $\mathrm{S}-\mathrm{SiC}$, is made by Céramiques \& Composites (France) and is naturally sintered: the powders are pressed and then heated to $2000{ }^{\circ} \mathrm{C}$. During processing, small quantities of boron carbide $\left(\mathrm{B}_{4} \mathrm{C}\right)$ are added to improve the sintering process. The porosity was evaluated by Riou (1996) and is reported in Table 2. The presence of structural defects and carbon precipitates can be seen on a TEM picture shown in Fig. 1a. The second grade, referred to as $\mathrm{SiC}-\mathrm{B}$ and made by CERCOM (USA), is obtained by pressure-assisted densification: the ceramic is heated to $2000{ }^{\circ} \mathrm{C}$ under a pressure of $18 \mathrm{MPa}$. The intergranular alumina phase eliminates the porosity. One can also notice the presence of metallic precipitates (Fe, V, Ti, Cr) and boron (B) as well as traces of microplasticity caused by processing (Fig. 1b). The presence of an intergranular alumina phase in
Table 2

Mechanical properties of two $\mathrm{SiC}$ grades

\begin{tabular}{lll}
\hline Material property & S-SiC & SiC-B \\
\hline Young's modulus, $E(\mathrm{GPa})$ & 410 & 455 \\
Poisson's ratio, $v$ & 0.16 & 0.16 \\
Mass density, $\rho\left(\mathrm{kg} / \mathrm{m}^{3}\right)$ & 3150 & 3200 \\
Porosity & $1.8 \%$ & 0 \\
Toughness, $K_{\mathrm{Ic}}(\mathrm{MPa} \sqrt{\mathrm{m}})$ & 3.2 & 5.2 \\
Weibull modulus, $m$ & 9.3 & 21 \\
Average failure stress, $\sigma_{\mathrm{w}}(\mathrm{MPa})$ & 370 & 520 \\
Effective volume $\left(\mathrm{mm}^{3}\right)$ & 1.7 & 0.4 \\
Number of tests & 65 & 29 \\
\hline
\end{tabular}

$\mathrm{SiC}-\mathrm{B}$ and porosity in $\mathrm{S}-\mathrm{SiC}$ explains the differences concerning the mechanical properties of the two $\mathrm{SiC}$ grades listed in Table 2.

The microstructure of the two ceramics also induces important consequences regarding 3-point bend test results: the behaviour of ceramics under a tensile loading is elastic, brittle and probabilistic. With reference to a structure $\Omega$, one can define the cumulative failure probability $P_{\mathrm{F}}$ as

$P_{\mathrm{F}}=1-\exp \left[-V_{\text {eff }} \lambda_{0}\left(\frac{\left\langle\sigma_{\mathrm{F}}\right\rangle}{S_{0}}\right)^{m}\right]$

where $\sigma_{\mathrm{F}}$ is the failure stress, i.e., the maximum value in $\Omega$ of the first principal stress $\sigma_{1}(\underline{x})$ (where $\sigma_{1}(\underline{x}) \geqslant \sigma_{2}(\underline{x}) \geqslant \sigma_{3}(\underline{x})$ are the principal stresses), $m$ the Weibull modulus and $S_{0}^{m} / \lambda_{0}$ the Weibull scale parameter. The effective volume $V_{\text {eff }}$ (Davies, 1973) depends on the stress field and the Weibull modulus $m$

$V_{\text {eff }}=\int_{\Omega}\left[\frac{\left\langle\sigma_{1}(\underline{x})\right\rangle}{\left\langle\sigma_{\mathrm{F}}\right\rangle}\right]^{m} \mathrm{~d} \omega$

where $\langle\cdot\rangle$ are the Macauley brackets. The average failure strength $\sigma_{\mathrm{w}}$ and the corresponding standard deviation $\sigma_{\text {sd }}$ are expressed as

$\sigma_{\mathrm{w}}=S_{0}\left(\frac{V_{0}}{V_{\mathrm{eff}}}\right)^{1 / m} \Gamma\left(1+\frac{1}{m}\right)$
$\sigma_{\mathrm{sd}}=S_{0}\left(\frac{V_{0}}{V_{\mathrm{eff}}}\right)^{1 / m} \sqrt{\Gamma\left(1+\frac{2}{m}\right)-\Gamma^{2}\left(1+\frac{1}{m}\right)}$

where $\Gamma$ is the Euler function of the second kind (Spanier and Oldham, 1987). The results of 3-point 

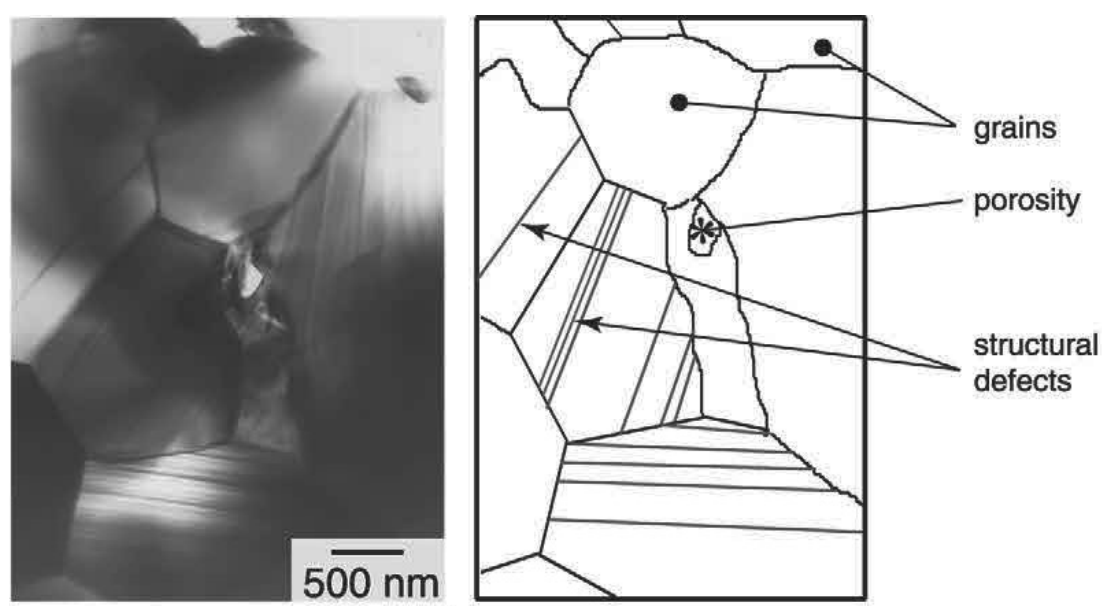

(a)
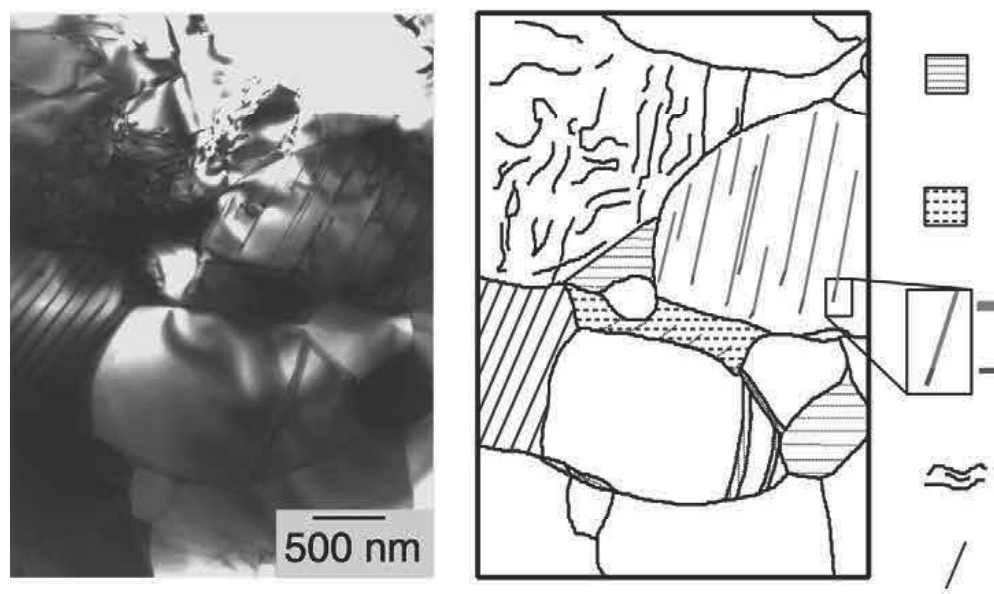

metallic

precipitates

( $\mathrm{Fe}, \mathrm{Cr}, \mathrm{Ti}, \mathrm{V})$

alumina

precipitates

stacking faults

partial

dislocations

dislocations

structural

defects

(b)

Fig. 1. TEM micrographs of an $\mathrm{S}-\mathrm{SiC}$ (a) and $\mathrm{SiC}-\mathrm{B}$ (b) specimen.

bend tests are summarised in Table 2. The corresponding effective volume is given by

$V_{\text {eff }}=\frac{V}{2(m+1)^{2}}$

where $V$ is the loaded volume. For $\mathrm{S}-\mathrm{SiC}$ samples, flaws initiating failure were identified. These flaws were found by following hackles generated by transgranular fracture and by looking for the mirror zone that surrounds the flaw. The flaws generally observed are sintering defects (Fig. 2). The presence of sintering flaws in $\mathrm{S}-\mathrm{SiC}$ samples induces a low average failure strength and a low Weibull modulus. The processing of SiC-B eliminates the sintering flaws and leads to intergranular failure. The failure behaviour of $\mathrm{SiC}-\mathrm{B}$ is "more" deterministic; the Weibull modulus as well as the average failure strength are higher than those observed in S-SiC samples (Table 2).

\section{Quasi-static compression tests}

Numerous types of samples were developed to apply a state of quasi-static uniaxial compression. All set-ups aim at creating a volume as big as possible (in comparison with the specimen volume) where the failure criterion is maximum (in absolute value), as uniaxial as possible and as homogeneous as possible. Moreover, the geometry must limit 


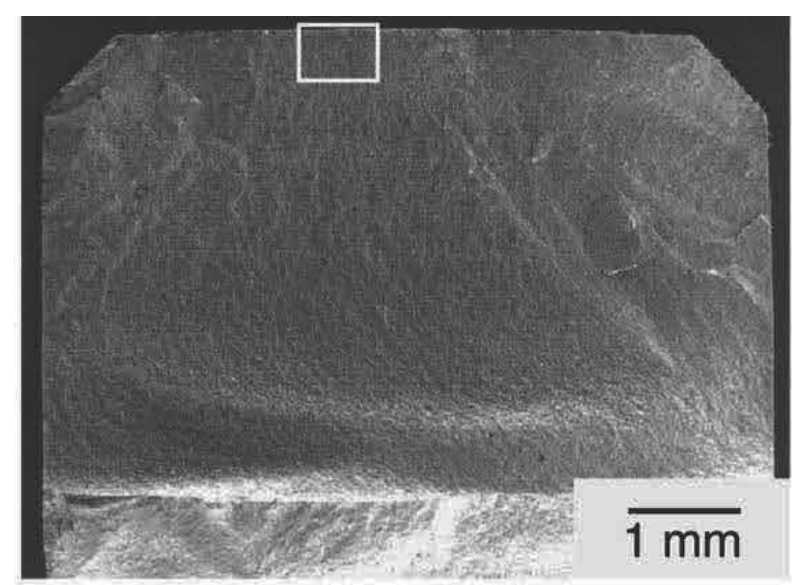

(a)

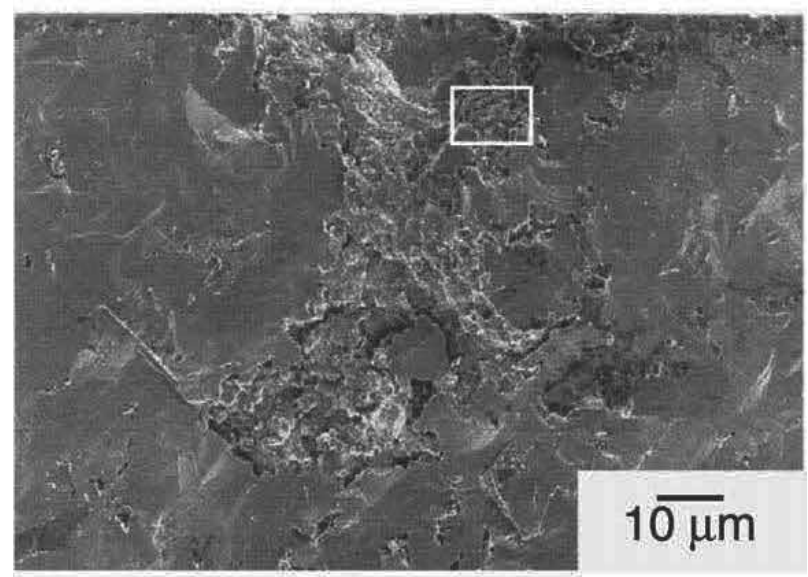

(b)

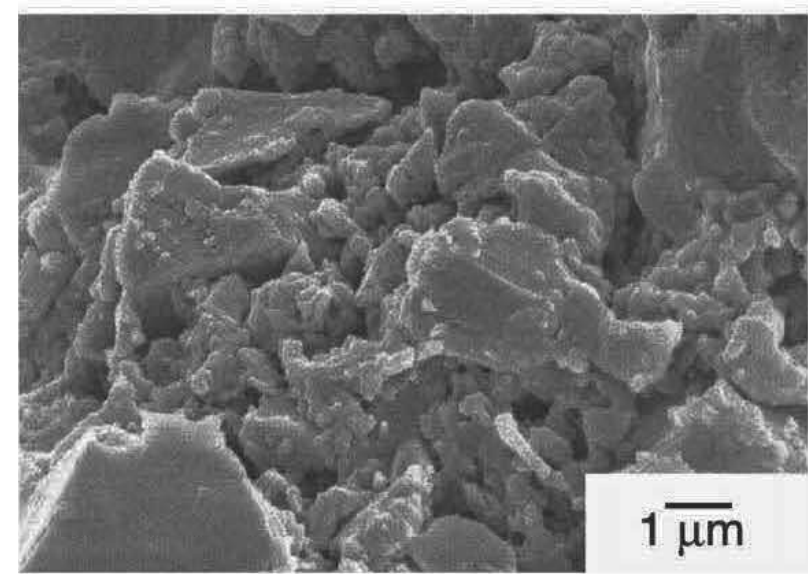

(c)

Fig. 2. Typical failure defect in an S-SiC ceramic: general view (a), first zoom (b) and second zoom (c).

tensile stresses in the specimen below the tensile failure stress (see Table 2).
Lankford performed uniaxial compressive tests with $\mathrm{SiC}$ and alumina samples in a large strain rate range (Lankford, 1981) and temperature range (Lankford, 1982). In these tests, a cylinder with perfectly parallel and polished surfaces is used (Lankford, 1977). Platens are made of AD999 alumina for alumina specimen, and $\mathrm{SiC}$ for $\alpha$-SiC specimen, respectively. Thin discs made of high-strength steel are put between the specimen and platens to reduce a "barrel effect," i.e., the radial and orthoradial stresses in the specimen. The compressive strength of $\alpha-\mathrm{SiC}$ is shown to be constant (Lankford, 1981) for strain rates less than $100 \mathrm{~s}^{-1}$ and equal to $-4.0 \mathrm{GPa}$. Failure is caused by the growth and coalescence of axial microcracks that are generated from voids (Lankford, 1991). Split Hopkinson bars allow for higher strain rates. The compressive strength $\sigma_{\text {comp }}$ of $\mathrm{SiC}$ samples is increasing with strain rate $\left(\left|\sigma_{\text {comp }}\right| \propto|\dot{\varepsilon}|^{0.26}\right)$ for $|\dot{\varepsilon}|>200 \mathrm{~s}^{-1}$ (Lankford, 1981). This phenomenon may be explained by inertia effects (Grady and Lipkin, 1980) $\left(\left|\sigma_{\text {comp }}\right| \propto|\dot{\varepsilon}|^{1 / 3}\right)$.

Dunlay et al. (1989) performed quasi-static uniaxial compressive tests on different kinds of ceramics. Two types of silicon carbide were used: $\alpha$-SiC (purity: 98.5\%, $\rho=3120 \mathrm{~kg} / \mathrm{m}^{3}$, existing pores, $\left.\sigma_{\mathrm{w}}=312 \mathrm{MPa}, m=10.8\right)$ was already used by Lankford (1981) and SiC-HP obtained by a pressure-assisted densification (purity: 95\%, $\rho=$ $3320 \mathrm{~kg} / \mathrm{m}^{3}$, no porosity, tensile strength: $\sigma_{\mathrm{w}}=694$ $\mathrm{MPa}, m=9.6$ ). The nominal compressive failure stresses are given in Table 1. Moreover, to improve quasi-static uniaxial compression tests, the authors took additional precautions to such a point that Lankford (1991) stated that they "performed probably the most perfect compression tests yet reported for strong ceramics:" WC anvils characterised by a high compressive strength ( -4.5 $\mathrm{GPa}$ ) were used. Their low compliance creates a small bicompression around the contact surface. Strict parallelism and alignment tolerances were enforced. The reduced-section specimen design (hourglass shape) allowed for the increase of the ratio between the compressive stresses and the radial and hoop tensile stresses.

Cosculluela (1992) also tried several types of specimen designs. Alumina samples were 
compressed with WC anvils at a very low strain rate $\left(|\dot{\varepsilon}|<10^{-5} \mathrm{~s}^{-1}\right)$. These different tests showed that cone-shaped anvils give better results than cylindrical ones. This result seems to indicate that tensile stresses led to failure at least for the first kind of tests. For example, the compressive strength obtained with a cylindrical specimen was about -2.7 GPa (AL23 alumina). With a hyperbola-shaped specimen without head, a $-3.15 \mathrm{GPa}$ compressive strength was found (T299 alumina) whereas hourglass specimen with cylindrical end caps reached $-3.2 \mathrm{GPa}$ (T299 alumina) and -3.5 GPa (AL23 alumina), respectively.

More recently, Lamaison (1997) used $\mathrm{TiB}_{2}$ cylindrical specimen with cone-shaped anvils char- acterised by a low angle. This geometry leads to lower (in absolute value) failure stresses ( -2.4 $\mathrm{GPa})$ than the dog-bone geometry $(-4.1 \mathrm{GPa})$. No strain rate dependence was found in the measured range $\left(10^{-3}<|\dot{\varepsilon}|<500 \mathrm{~s}^{-1}\right)$. Dog-bone samples were also used by Bourne et al. (1997) for two SiC grades ( $\mathrm{S}-\mathrm{SiC}$ and $\mathrm{SiC}-\mathrm{B}$ ). The compressive strength obtained during quasi-static tests $(|\dot{\varepsilon}|=$ $\left.10^{-3} \mathrm{~s}^{-1}\right)$ and with split Hopkinson bars $(|\dot{\varepsilon}|=600$ $\mathrm{s}^{-1}$ ) are reported in Table 1. Steel collars were heat shrunk onto the end diameters of both types of specimens to prevent premature failure due to specimen/platen interactions.

To summarise, it appears that for the specimen geometry, the precautions taken concerning the

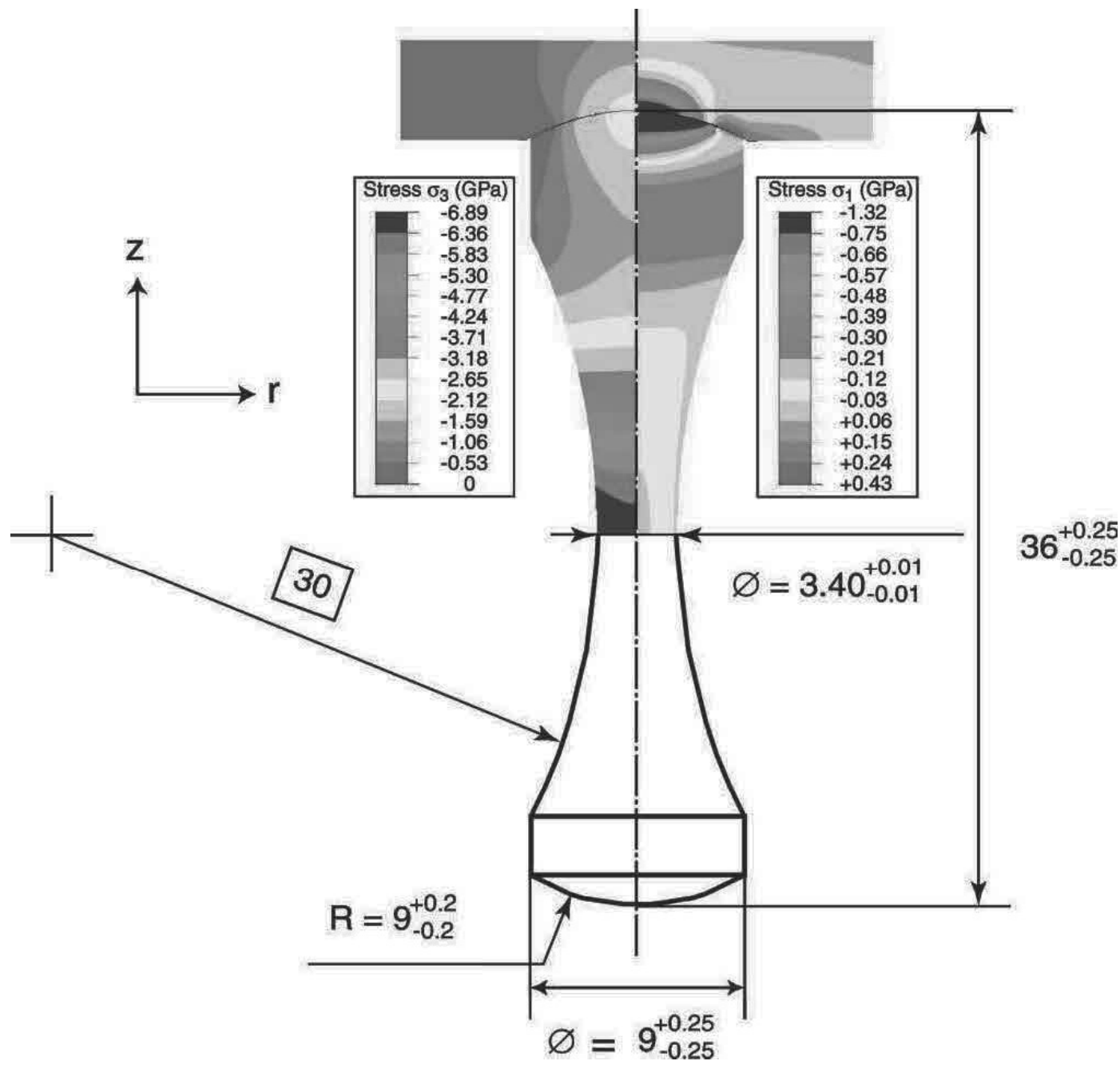

Fig. 3. Specimen geometry in compression, third $\left(\sigma_{3}\right)$ and first $\left(\sigma_{1}\right)$ principal stress distributions. 
specimen/anvils interfaces seem to have a significant influence on the measured compressive strength. The dog-bone geometry, by increasing the ratio between the maximum compressive axial stress and the radial and orthoradial tensile stresses, allows one to reduce the influence of specimen/ anvil contact. It also induces a better uniaxial and uniform stress field. Fig. 3 shows the sample geometry used in the uniaxial compression tests reported herein. The first and third principal stress fields computed with the Finite Element code Abaqus Implicit (Hibbitt et al., 1998) are also shown. This dog-bone geometry reduces the stress concentrations. Axial stresses in the specimen centre are perfectly homogeneous.

Moreover, as it was observed in tension, the effective volume mainly depends on the stress concentrations and the Weibull modulus. Consequently, this geometry increases the gauge volume in comparison with a cylindrical specimen. Near the centre of the specimen, the radial and hoop stress levels are more than 50 times less than that of compressive stress (in absolute value). Therefore, near the centre of the specimen, compression can be considered uniaxial. Finally greased aluminium caps were inserted between the specimen and the anvils. Fig. 4 shows the maximum value of the first and third principal stresses in each section (perpendicular to the specimen axis) as a function of the axial co-ordinate of each section. The third principal stress is the largest (in absolute value) and almost constant near the centre of the speci-

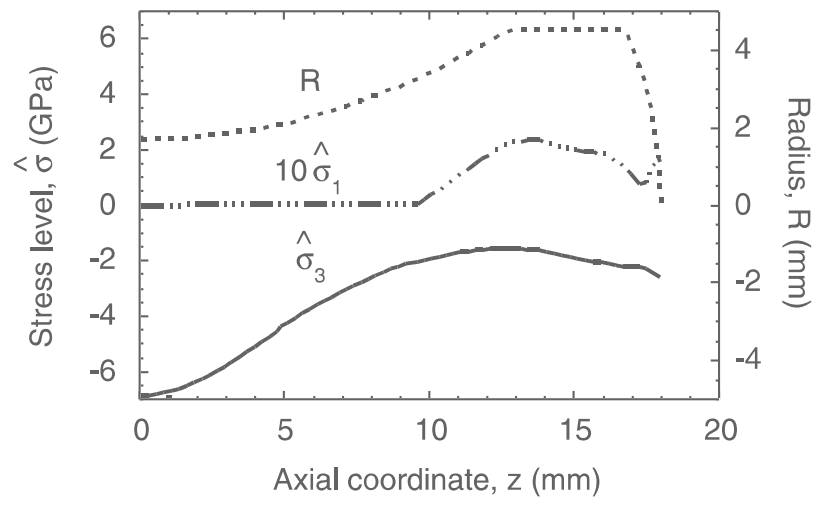

Fig. 4. Maximum value for each section characterised by an outer radius $R$ of the first $\left(\hat{\sigma}_{1}\right)$, third $\left(\hat{\sigma}_{3}\right)$ principal stresses as a function of the axial position $z$ of the section. men whereas the first principal stress is positive and maximum in the heads of the specimen. The curvature radius of the hourglass surface is greater than the transition radius consisting of a cylindrical part and heads. This transition radius has several advantages: the maximum third principal stress, the maximum axial stress and the nominal axial stress are almost identical. Moreover, around the locus where the compressive stress is maximum, the third principal stress is homogeneous and the two other ones are smaller (in absolute value).

To monitor the compression tests, a high-speed camera is used. Since the tensile strength is probabilistic and the compression is quasi-static, it is not possible to know in advance when failure may happen. To trigger the flashlight, the signal derivative given by a gauge located near the head of the specimen is used. The first picture is shot few microseconds after the beginning of the failure process when the signal derivative becomes significant. By comparing samples made of $\mathrm{S}-\mathrm{SiC}$ and $\mathrm{SiC}-\mathrm{B}$ ceramics, the same conclusions can be drawn when looking at the pictures shot by the high-speed camera. A debris projection all around the specimen is observed (Fig. 5). This appears to be puzzling if one considers that a point defect initiates failure. But the pattern of debris ejection and cracking is not completely axisymmetric for three reasons. First, the projections on the lefthand side (LHS) of Fig. 5b and c are faster than the projections on the right-hand side (RHS). Second, the projections on the LHS are closer to the centre than the projection on the RHS. Third, some visible cracks start at the RHS, moving away from the centre and cross the specimen by bending into a curve. The photographs also confirm that failure did not initiate in the head of the specimen. Fig. 6 shows the covered distance by the debris as a function of time. For $\mathrm{SiC}-\mathrm{B}$ ceramics, the highest velocity (on the LHS) is about $500 \mathrm{~m} / \mathrm{s}$ and the lowest velocity (on the RHS) is of the order of 150 $\mathrm{m} / \mathrm{s}$. Conversely, for $\mathrm{S}-\mathrm{SiC}$ ceramics, the highest velocity of projection is about $250 \mathrm{~m} / \mathrm{s}$ (on the LHS) and its lowest velocity reaches about $130 \mathrm{~m} / \mathrm{s}$ (on the RHS). Correlation between the asymmetric pattern and the asymmetric projection velocity is observed each time. By extrapolating the radial 


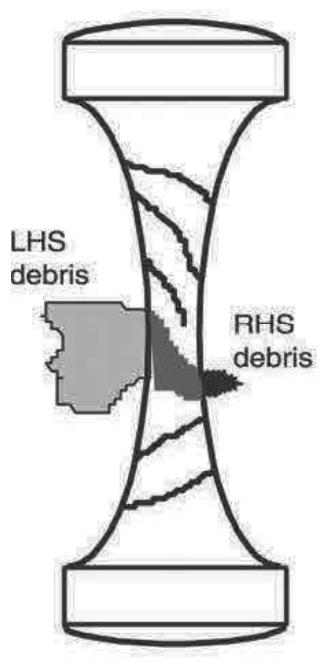

(a)

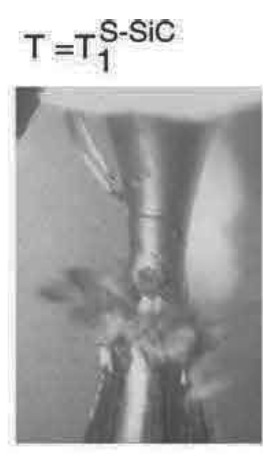

$\mathrm{T}=\mathrm{T}_{1}^{\mathrm{S}-\mathrm{SiC}}+6 \mu \mathrm{s}$

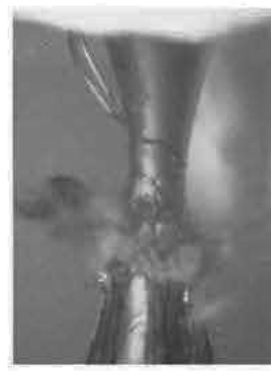

(b)

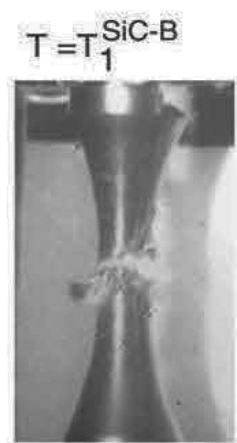

(c)

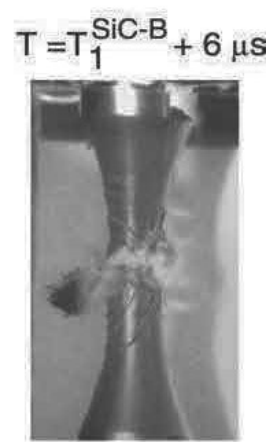

Fig. 5. Location of the RHS and LHS debris (a). Series of pictures shot during a compression test on $\mathrm{S}-\mathrm{SiC}$ (b, failure stress $=-7$ $\mathrm{GPa}$ ) and $\mathrm{SiC}-\mathrm{B}$ (c, failure stress $=-6 \mathrm{GPa}$ ) samples.

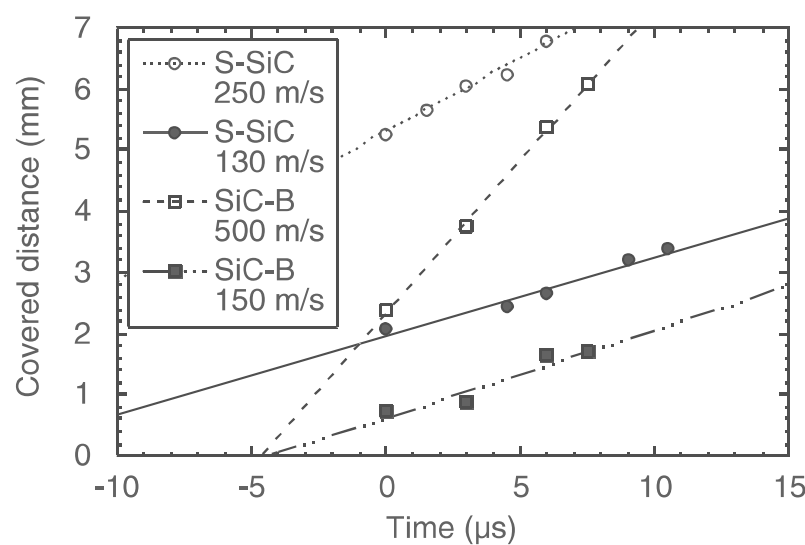

Fig. 6. Covered distance versus time for two $\mathrm{SiC}$ samples and corresponding velocities on the RHS and LHS (Fig. 5a). The measurements (open and closed symbols) are deduced from the analysis of the complete sequence of pictures shot during the experiments, part of which is shown in Fig. 5.

displacement of debris on the RHS of Fig. $5, T_{1}^{\mathrm{S}-\mathrm{SiC}}$ and $T_{1}^{\mathrm{SiC}-\mathrm{B}}$ were found to be equal to 15 and $4 \mu \mathrm{s}$, respectively, where $T_{1}$ denotes the time duration between the inception of failure and the first photograph of Fig. 5.

A thin S-SiC strip was cut out of a specimen loaded at $-6.5 \mathrm{GPa}$ and unloaded before failure. After TEM examinations, neither intergranular nor transgranular cracks, nor traces of additional microplasticity could be observed. Concerning the absence of cracks and microplasticity, two explanations are possible: either the thin strip removed near the centre of the specimen is not located within the damaged zone (this is very unlikely as will be shown below) or the compressive stress level was not sufficient to induce damage within the specimen. Similarly, a thin SiC-B strip was cut out of a specimen loaded at $-6.0 \mathrm{GPa}$ and unloaded. As for S-SiC, no cracking was found. It is expected that failure in compression occurs suddenly with no "warning" signals on a macroscopic level (e.g., non-linear stress-strain response) or on a microscopic level (as shown by TEM analyses).

A procedure was developed to keep all the fragments after failure and allowed us to observe 
them. Before the compression tests, the specimen is embedded in an annulus made of Wood metal characterised by a low melting temperature (i.e., $T_{\mathrm{f}}=73^{\circ} \mathrm{C}$ ), a low yield stress (i.e., $\sigma_{\mathrm{y}}=40 \mathrm{MPa}$ ) and a small Young's modulus (i.e., $E=50 \mathrm{GPa}$ ). Due to its mechanical properties, the Wood metal does not influence the stress field in the specimen (the radial stress reaches around $-120 \mathrm{MPa}$ within the centre without Wood metal, see Fig. 3). Moreover, the average compressive strength of five embedded specimens was only $2 \%$ greater than the overall average. Concerning S-SiC, several zones can be observed (Fig. 7a). The first zone is characterised by a high density of cracking in every direction. It spreads out along the outer surface and near the centre of the specimen. This observation proves that the central part of the specimen is fully damaged and confirms the hypothesis made previously to state that the failure in a compressive test is brittle. The presence of numerous vertical cracks on all sides of the first zone, which are then connected by some horizontal cracks, can also be seen. For the SiC-B grade, the same zone near the centre characterised by a high density of cracking. But the cracks on all sides of this first zone are less numerous than with $\mathrm{S}-\mathrm{SiC}$. Moreover few big cracks move away from the RHS of the first zone and cross the specimen by bending into a curve (Fig. 7b).

By using the hypothesis of a failure due to tensile stresses induced by the compressive loading, two effective volumes associated with the tensile stresses are computed by using Eq. (3) for two boundary conditions (Table 3). The Weibull parameters obtained in 3-point bending (Table 2) are used. The first boundary condition corresponds to a uniform pressure applied on the spherical part of the specimen. The second modelling uses a contact boundary condition between the specimen and the anvils as shown in Fig. 3. The presence of aluminium foils inserted between the specimen and the anvils probably induce stresses "in between" these two computations. The average tensile failure stress is then calculated according to Eq. (4), from which the corresponding nominal compressive strength can be determined. Table 3

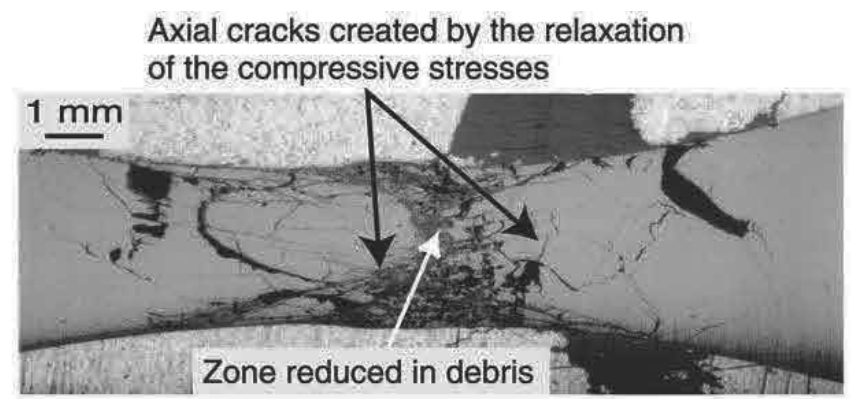

(a)

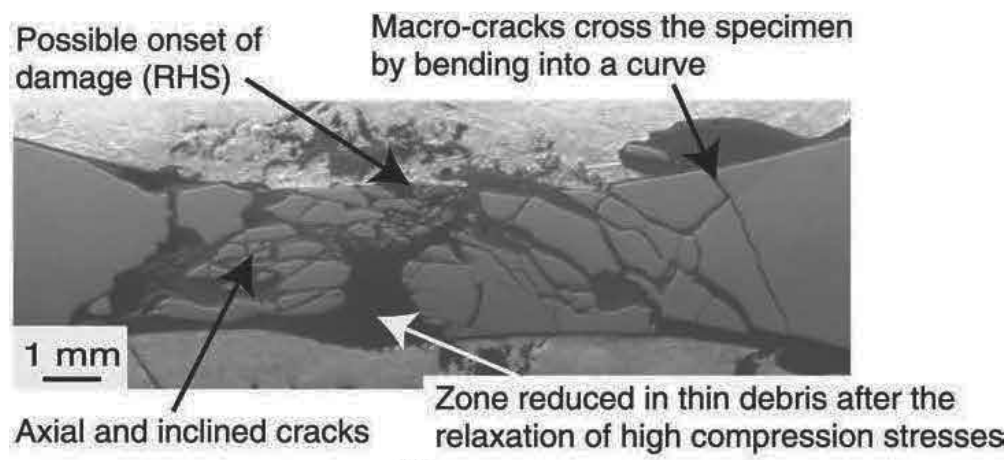

(b)

Fig. 7. Post-mortem macrographs of S-SiC (a) and SiC-B (b) samples loaded in uniaxial compression. 
Table 3

Failure properties in compression of two $\mathrm{SiC}$ grades

\begin{tabular}{|c|c|c|}
\hline Material property & $\mathrm{S}-\mathrm{SiC}$ & $\mathrm{SiC}-\mathrm{B}$ \\
\hline Weibull modulus, $m$ & 13 & 12.5 \\
\hline Average failure stress, $\sigma_{\text {comp }}(\mathrm{GPa})$ & -6.5 & -5.8 \\
\hline Number of tests & 19 & 23 \\
\hline $\begin{array}{l}\text { Effective volume with the first } \\
\text { boundary condition }\left(\mathrm{mm}^{3}\right)\end{array}$ & 17 & 3.9 \\
\hline $\begin{array}{l}\text { Prediction of average failure stress } \\
\text { with the first boundary condition, } \\
\sigma_{\text {comp }}(\mathrm{GPa})\end{array}$ & -10.7 & -15.2 \\
\hline $\begin{array}{l}\text { Effective volume with the second } \\
\text { boundary condition }\left(\mathrm{mm}^{3}\right)\end{array}$ & 140 & 58 \\
\hline $\begin{array}{l}\text { Prediction of average failure stress } \\
\text { with the second boundary } \\
\text { condition, } \sigma_{\text {comp }}(\mathrm{GPa})\end{array}$ & -6.7 & -11.6 \\
\hline
\end{tabular}

summarises the values of the nominal compressive strength for the $\mathrm{S}-\mathrm{SiC}$ and $\mathrm{SiC}-\mathrm{B}$ grades with the two boundary conditions. For the $\mathrm{S}-\mathrm{SiC}$ grade, the nominal strength level is reasonably predicted with the second boundary condition. However, the apparent Weibull modulus is greater than that observed in 3-point bend tests. For the other grade, the predictions are not in agreement with the measurements. Furthermore, if these predictions were correct, failure should occur in the heads of the specimen. This fact is contradicted by the observations shown in Figs. 5 and 7. Contrary to 3-point bend tests, the Weibull moduli are virtually identical. In addition, the average strength of $\mathrm{S}-\mathrm{SiC}$ is greater than that of $\mathrm{SiC}-\mathrm{B}$, whereas the 3 -point bend tests showed opposite results. Section 4 aims at explaining all these observations by using an anisotropic damage model since a Weibull analysis alone cannot be used.

\section{Numerical analysis of the compressive behaviour of two $\mathrm{SiC}$ grades}

Fig. 7 shows that the compression tests reported herein lead to fully fragmented samples during a few microseconds. Consequently, a damage model able to capture these phenomena is used to understand the chronology of degradation events.

\subsection{Damage model}

An anisotropic damage description is used (Denoual and Hild, 1998, 2000) under the hypothesis of high strain rates. For each principal stress direction $\underline{d}_{i}$, a damage variable $D_{i}$ is defined so that the principal strains $\varepsilon_{i}$ are related to the principal stresses $\Sigma_{i}$ by: $\varepsilon_{i}=S_{i j}\left(D_{1}, D_{2}, D_{3}\right) \sigma_{j}$, where the usual index summation is used. The compliance tensor $\underline{\underline{S}}$ is written in the principal frame $\left(\underline{d}_{1}, \underline{d}_{2}, \underline{d}_{3}\right)$

$\underline{\underline{S}}=\frac{1}{E}\left[\begin{array}{ccc}\frac{1}{1-D_{1}} & -v & -v \\ -v & \frac{1}{1-D_{2}} & -v \\ -v & -v & \frac{1}{1-D_{3}}\end{array}\right]$

where $E$ is the Young's modulus of the undamaged material. The kinetic law for each independent damage variable $D_{i}$ (i.e., no index summation is used here) is expressed in a differential form to be implemented in a finite element code

$$
\begin{gathered}
\frac{\mathrm{d}^{2}}{\mathrm{~d} t^{2}}\left(\frac{1}{1-D_{i}} \frac{\mathrm{d} D_{i}}{\mathrm{~d} t}\right)=6 \lambda_{t}\left(\tilde{\sigma}_{i}\right) S\left(k C_{0}\right)^{3} \\
\text { when } \tilde{\sigma}_{i}>0 \text { and } \frac{\mathrm{d} \tilde{\sigma}_{i}}{\mathrm{~d} t}>0
\end{gathered}
$$

where $S$ is a shape parameter, $\tilde{\sigma}_{i}$ the effective stress $\left(\tilde{\sigma}_{i}=\sigma_{i} /\left(1-D_{i}\right)\right.$ (Lemaitre, 1992)), $k C_{0}$ the velocity of propagating cracks, $\lambda_{t}$ the defect density associated to the Weibull model and expressed as

$$
\begin{aligned}
& V_{\mathrm{FE}} \lambda_{t}\left(\tilde{\sigma}_{i}\right) \\
& = \begin{cases}0 & \text { if } \tilde{\sigma}_{i}<\sigma_{\mathrm{f}} \\
\max \left[V_{\mathrm{FE}} \lambda_{0}\left(\frac{\tilde{\sigma}_{i}}{S_{0}}\right)^{m}, 1\right] & \text { otherwise }\end{cases}
\end{aligned}
$$

where $V_{\mathrm{FE}}$ is the volume of the considered finite element. The value $\sigma_{\mathrm{f}}$ is a stress obtained by random selection of a real $P_{\mathrm{F}}$ lying between 0 and 1 and by applying Eq. (2) when $V_{\mathrm{FE}}=V_{\text {eff }}$. Eq. (9) expresses the average number of broken defects within a volume $V_{\mathrm{FE}}$ which is equal to 0,1 or greater than 1. The integration of Eq. (8) usually assumes zero initial conditions.

For low stress rates, in the considered finite element, when the local principal stress $\tilde{\sigma}_{i}$ reaches the random failure stress $\sigma_{\mathrm{f}}$, damage is increasing faster than the loading stress. The ultimate 
strength, which is close to the random failure stress $\sigma_{\mathrm{f}}$, is probabilistic and obeys the Weibull law given in Eq. (2). The strength can be characterised by a standard deviation (Eq. (5)) and by an average value (Eq. (4)) that is stress rate independent (Fig. 8). At higher stress rates, damage is not changing as fast as the loading stress. Consequently, the ultimate stress is independent of the random failure stress $\sigma_{\mathrm{f}}$, becomes deterministic and stress rate sensitive. According to Eq. (8), if one considers a constant stress rate $\dot{\sigma}\left(\tilde{\sigma}_{i}=\dot{\sigma} t\right)$, any damage parameter $D_{i}$ can be expressed as a function of the corresponding effective stress $\tilde{\sigma}_{i}$

$D_{i}=1-\exp \left[-\frac{6 m !}{(m+3) !}\left(\frac{\tilde{\sigma}_{i}}{\sigma_{\mathrm{c}}}\right)^{m+3}\right]$

with

$\sigma_{\mathrm{c}}=\left[\frac{S_{0}^{m} \dot{\sigma}^{3}}{\lambda_{0} S\left(k C_{0}\right)^{n}}\right]^{1 /(m+3)}$

where $\sigma_{\mathrm{c}}$ denotes the characteristic strength (Denoual and Hild, 1998). The ultimate stress $\sigma_{\mathrm{u}}$, obtained when $\mathrm{d} \sigma_{i} / \mathrm{d} \tilde{\sigma}_{i}=0$, is given by

$\sigma_{\mathrm{u}}=\sigma_{\mathrm{c}}\left[\frac{(m+2) !}{6 e m !}\right]^{1 /(m+3)} \propto[\dot{\sigma}]^{3 /(m+3)}$

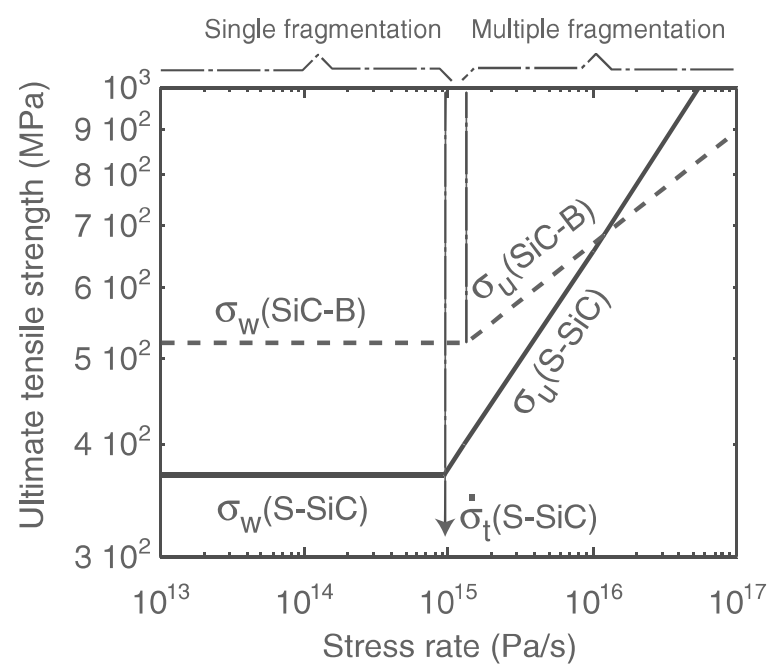

Fig. 8. Ultimate tensile stress of $\mathrm{S}-\mathrm{SiC}$ and $\mathrm{SiC}-\mathrm{B}$ as a function of stress rate predicted by using Eqs. (4) and (11) and data of Table 2. The single and multiple fragmentation regimes are shown and the transition is given by the condition $\sigma_{\mathrm{w}}=\sigma_{\mathrm{u}}$. where $e=\exp (1)$. In a $\log -\log$ plot showing the ultimate stress versus stress rate (Fig. 8), Eqs. (4) and (12) become straight lines that intersect when $\left(\sigma_{\mathrm{u}}=\sigma_{w}\right.$, i.e., $\left.\dot{\sigma}=\dot{\sigma}_{t}\right)$. If $\dot{\sigma} \leqslant \dot{\sigma}_{t}$ fragmentation is single (one crack is nucleated at failure), if $\dot{\sigma}>\dot{\sigma}_{t}$ fragmentation is multiple (many flaws are nucleated before the ultimate point is reached). For both $\mathrm{SiC}$ grades, the transition stress rate is of the order of $10^{15} \mathrm{~Pa} / \mathrm{s}$. According to Fig. 8, when the stress rate exceeds $10^{16} \mathrm{~Pa} / \mathrm{s}$, the ultimate stress of $\mathrm{S}-\mathrm{SiC}$ becomes greater than that of $\mathrm{SiC}-\mathrm{B}$. This constitutive model was implemented in the explicit finite element code Pamshock (2000).

\section{Roughness defect}

To model failure in a compression test, damage is assumed to be generated by tensile stresses due to the presence of surface roughness defects. In an earlier study (Forquin, 2000), it was shown that only defects close to surface are likely initiation sites. The roughness of a $\mathrm{SiC}-\mathrm{B}$ sample was measured parallel to the specimen axis. Fig. 9 shows a flaw of height of about $6 \mu \mathrm{m}$ that was used in the following modelling. This defect is representative of a whole population. The grinding process of $\mathrm{SiC}-\mathrm{B}$ samples is the same as that of $\mathrm{S}-\mathrm{SiC}$ samples. Therefore the population of roughness defects is probably the same. This fact may explain why the Weibull moduli are almost identical with $\mathrm{S}-\mathrm{SiC}$ and $\mathrm{SiC}-\mathrm{B}$ ceramics. This first study aims at

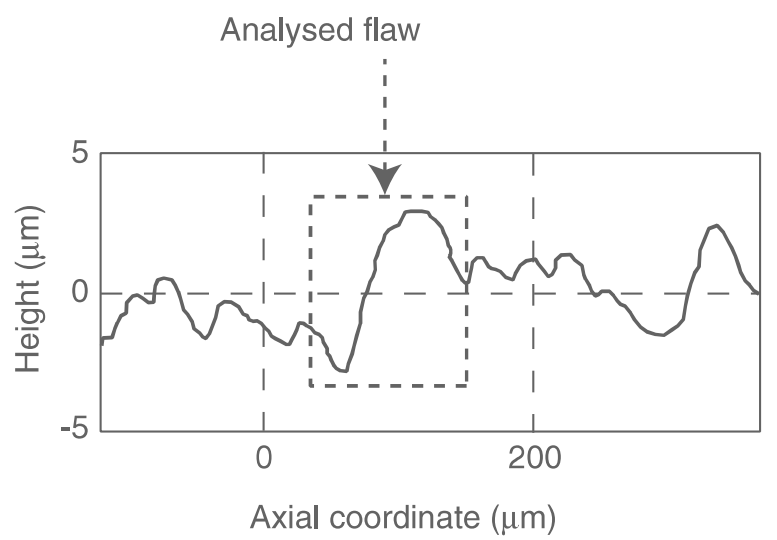

Fig. 9. Roughness profile measured in the axial direction of a compression specimen (S-SiC). 
understanding the effect of an isolated roughness defect on the compressive stress of a ceramic.

Damage appears for a compressive stress of $-13.6 \mathrm{GPa}$ for the S-SiC grade -12.1 GPa for the $\mathrm{SiC}-\mathrm{B}$ grade. Damage changes very rapidly. A speed of projections around $300 \mathrm{~m} / \mathrm{s}$ is obtained (Fig. 10). But the question is why, in compression,

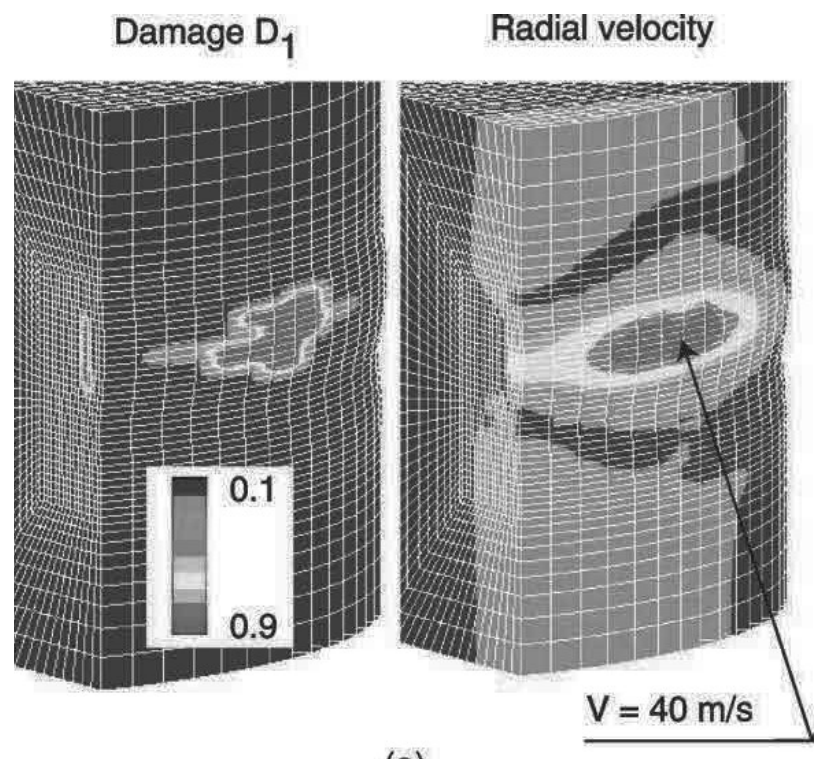

(a)

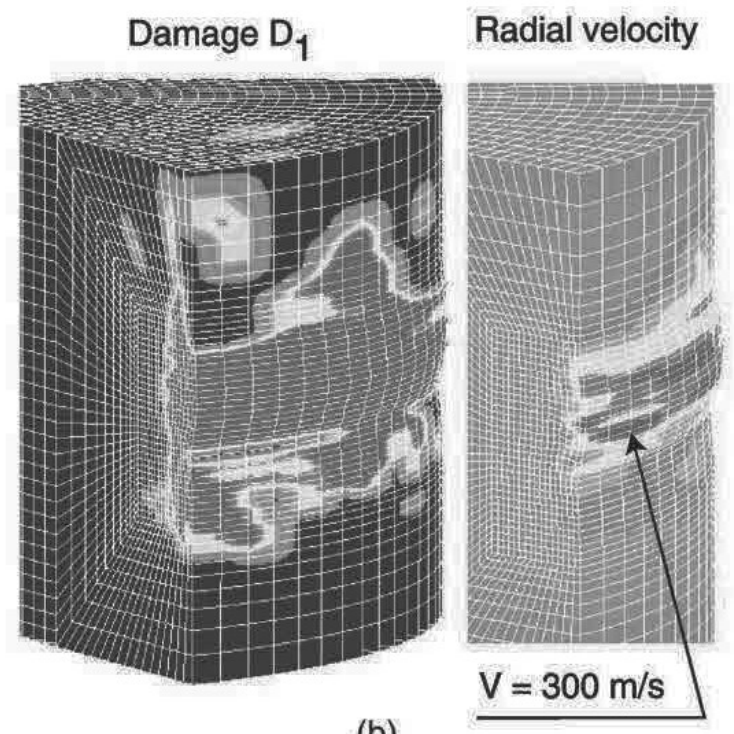

(b)

Fig. 10. Damage $\left(D_{1}\right)$ and radial velocity $(V)$ contours for two different times $(0.34$ and $0.37 \mu$ s, respectively) given by the simulation of a representative roughness defect submitted to a remote uniaxial compression $(\mathrm{S}-\mathrm{SiC})$.

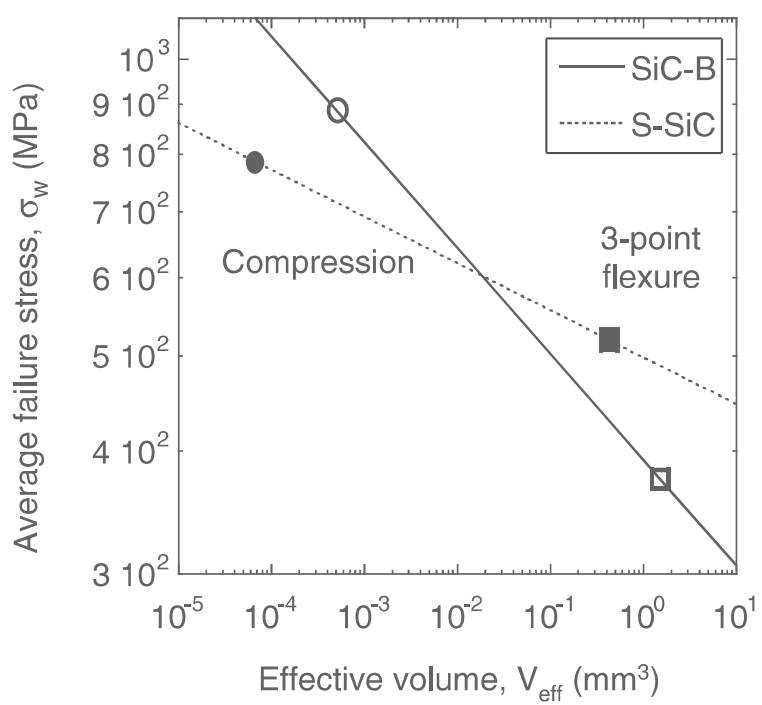

Fig. 11. Average tensile strength as a function of effective volume according to the Weibull model (Eq. (4)) in 3-point bending and in compression of a roughness defect for $\mathrm{S}-\mathrm{SiC}$ and $\mathrm{SiC}-\mathrm{B}$ ceramics

the $\mathrm{S}-\mathrm{SiC}$ average strength is higher than the $\mathrm{SiC}-$ $\mathrm{B}$ one? This fact can be explained by studying the tensile strength as a function of the effective volume with a roughness defect "in compression" (Fig. 11). It follows that the average tensile strength is proportional to the effective volume raised to the power $1 / m$ (see Eq. (4)). The $\mathrm{S}-\mathrm{SiC}$ line has a slope of $1 / 9.3$ in a log-log plot whereas the $\mathrm{SiC}-\mathrm{B}$ line has a slope of $1 / 21$ (Fig. 11). In 3-point bending, the $\mathrm{SiC}-\mathrm{B}$ average strength is greater than the $\mathrm{S}-\mathrm{SiC}$ one. The effective volumes generated by the presence of the roughness defects during a loading of compression are computed $\left(5.1 \times 10^{-4} \mathrm{~mm}^{3}\right.$ for $\mathrm{S}-\mathrm{SiC}$ and $6.7 \times 10^{-5} \mathrm{~mm}^{3}$ for $\mathrm{SiC}-\mathrm{B}$, respectively). For the compressive test, the $\mathrm{SiC}-\mathrm{B}$ average (tensile) strength $(790 \mathrm{MPa})$ is now less than the $\mathrm{S}-\mathrm{SiC}$ average (tensile) strength (885 $\mathrm{MPa}$ ). The hypothesis of failure caused by roughness explains that, in compression, the $\mathrm{S}-\mathrm{SiC}$ average compressive strength $(-6.7 \mathrm{GPa})$ is greater (in absolute value) than the $\mathrm{SiC}-\mathrm{B}$ grade $(-5.8$ $\mathrm{GPa}$ ). The ratio of average strength in tension due to a roughness defect is similar to the ratio of average strength in compression. The average compressive failure stresses predicted by the model are greater than those obtained experimentally. 
This model only concerns one roughness defect and not the whole specimen geometry. Consequently, the stress levels are only qualitative.

It can be noted that for $\alpha-\mathrm{SiC}$, for a Weibull modulus $m \approx 10.8$ (Dunlay et al., 1989), a stress (or strain) rate dependence of $3 /(3+m) \approx 0.22$ is expected (see Eq. (12)) to be compared with $\left|\sigma_{\text {comp }}\right| \propto|\dot{\varepsilon}|^{0.26}$. A reasonable prediction is obtained by using the scatter in tension, since it is the cause of multiple cracking in compression.

\section{Simulation of a compression test}

To simulate a compression test, opposite velocity fields are applied on each head. The velocity (i.e., $0.01 \mathrm{~mm} / \mu \mathrm{s}$ ) is sufficiently low to have a state of stress that is similar to a quasi-static loading condition. The mesh is shown in Fig. 12. The presence of a roughness defect generates a swelling that creates two tensile stress fields (Fig. 13): the first one is a hoop tensile stress field ( $\mathrm{M}_{1}$, Fig. 14), which induces a first degradation near the central plane. After a compression of about $-7.0 \mathrm{GPa}$, a second degradation pattern (Fig. 14) is generated

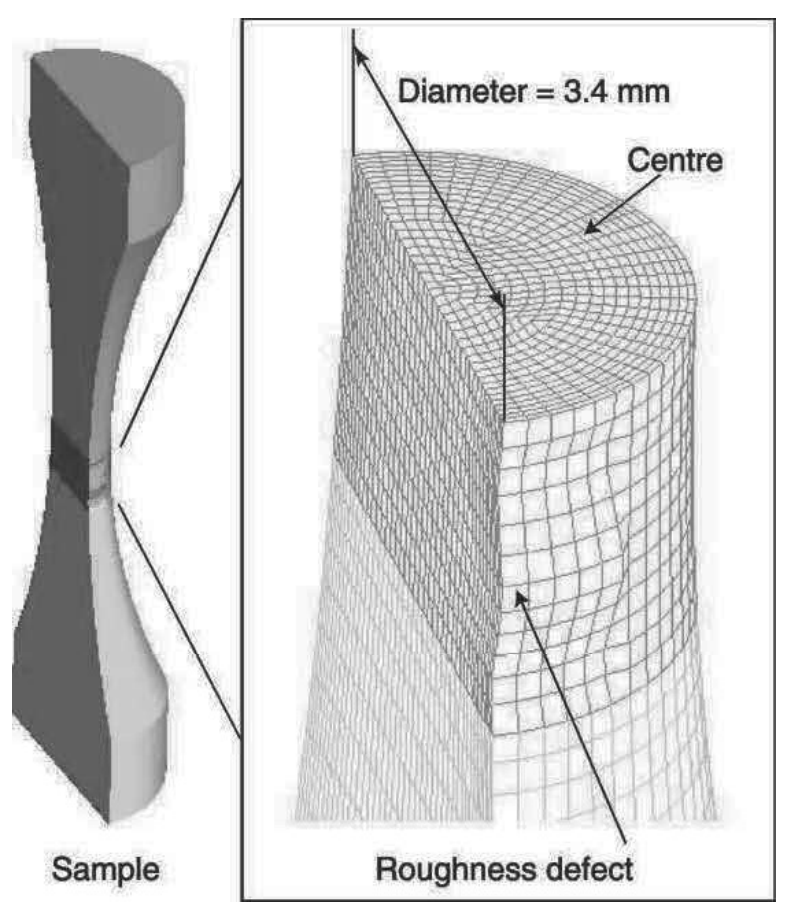

Fig. 12. Mesh and location of the roughness defect near the centre.

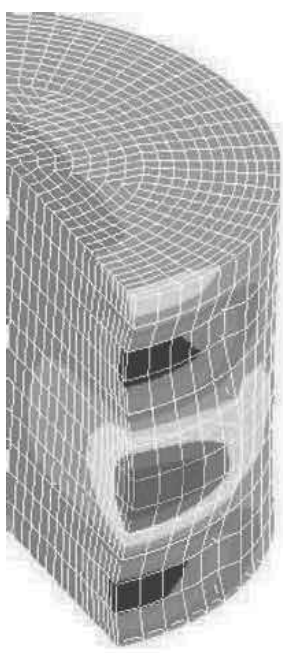

(a)

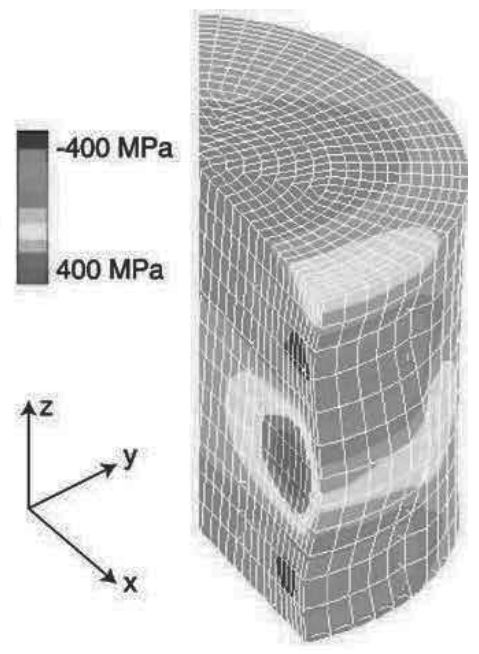

(b)
Fig. 13. Computed hoop (a) and radial (b) stress fields near the roughness defect when the remote compressive stress is equal to $-5 \mathrm{GPa}$ in $\mathrm{S}-\mathrm{SiC}$.

by a radial tensile stress field $\left(\mathrm{M}_{2}\right.$, Fig. 14). This damage induces a loss of stiffness in the radial direction and leads to a buckling type of instability. The elastic energy is now converted into kinetic energy. It induces a loss of stiffness in the axial direction that produces an axial relaxation. Two velocity fields converge at the same point with a speed of about $160 \mathrm{~m} / \mathrm{s}$. A radial velocity field with a speed of $150 \mathrm{~m} / \mathrm{s}$ is predicted (Fig. 14). The same value was observed on the RHS by means of the high-speed camera (Fig. 6). Damage propagates along the outer surface and reaches the opposite side (Fig. 14). Experimentally, the same phenomenon is observed: an axial relaxation and a radial velocity field with a speed of about $300 \mathrm{~m} / \mathrm{s}$ are generated (Fig. 5). The velocity measured with the high-speed camera (Fig. 6) is also predicted by the computation. The speed of projection is increasing while damage moves around the specimen axis because, while damage develops within the specimen, the undamaged volume decreases and accordingly, the axial stress increases in the undamaged volume (Fig. 15). The relaxation phenomenon is stronger. Two microseconds after the onset of degradation, the damage pattern is almost axisymmetric. Finally, damage invades the central zone of the specimen. A strong relaxation damages the ceramic in the three principal directions 


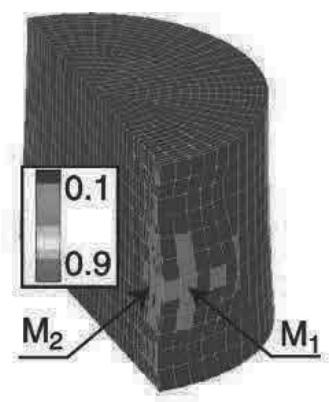

(a)

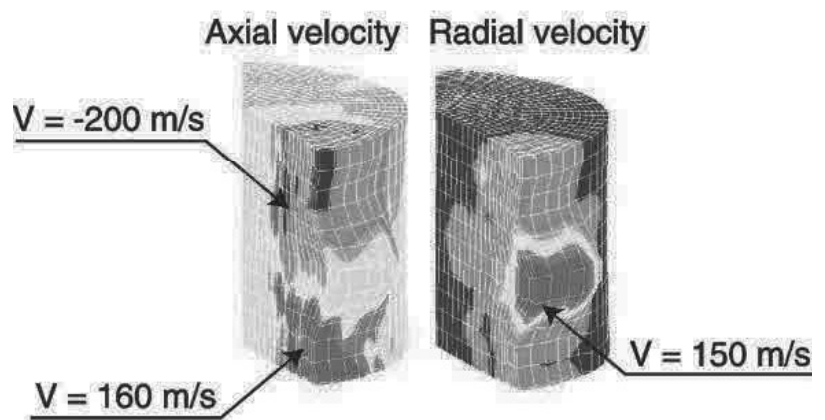

(b)

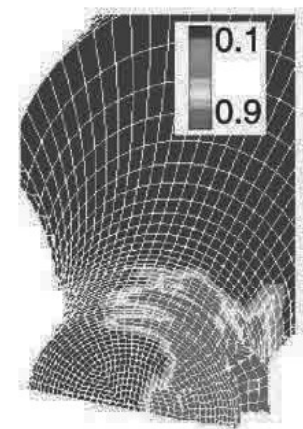

(c)

Fig. 14. Damage field $D_{1}$ when the remote compressive stress $=-6.3 \mathrm{GPa}$. This stage corresponds to failure initiation (a): damage grows slowly at point $\mathbf{M}_{1}$ and rapidly at point $\mathbf{M}_{2}$. Velocity fields during damage propagation (b, remote compressive stress $=-6.6 \mathrm{GPa}$ ). Damage field $D_{1}$ during damage propagation (c, remote compressive stress $=-7 \mathrm{GPa}$ ) in $\mathrm{S}-\mathrm{SiC}$.

between the roughness defect and the centre of the specimen (Fig. 16). The central zone is reduced into thin debris as shown on post-mortem studies (Fig. 7).

As observed in the post-mortem study and on the high-speed camera photographs, the modelling permits us to observe: the damage pattern, the shape of the zone reduced in debris, the timing of cracking $(<4 \mu$ s to fully damage the specimen). It

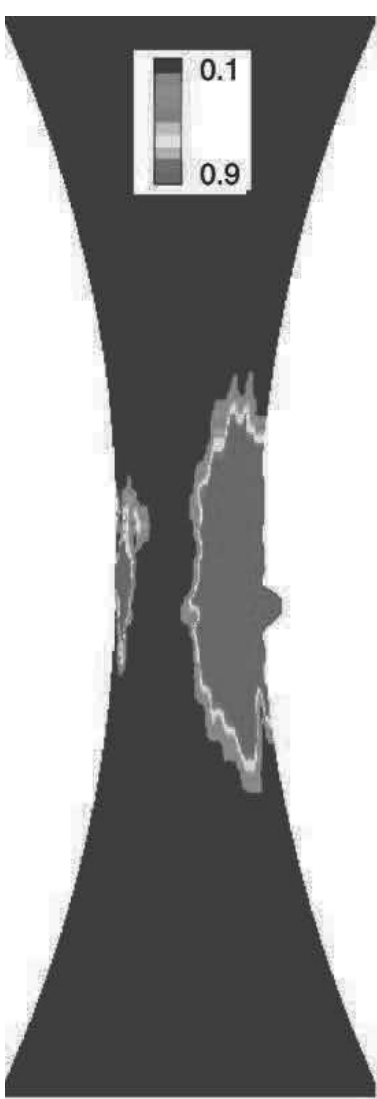

(a)

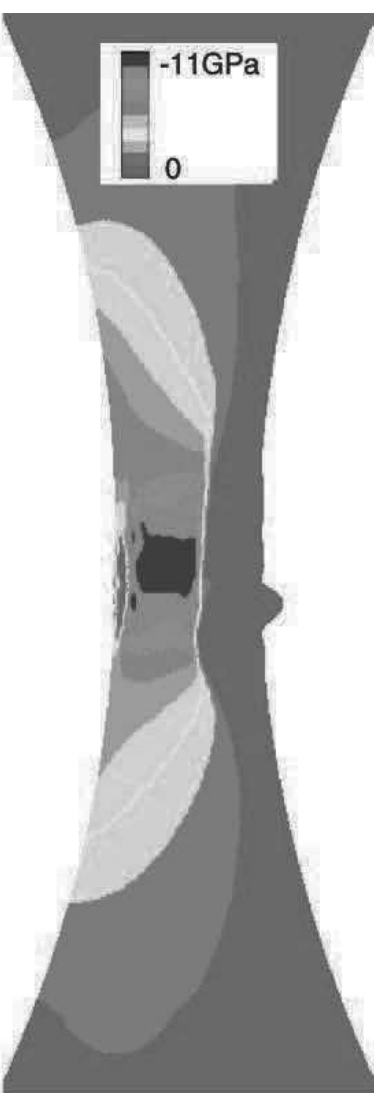

(b)
Fig. 15. Damage field $D_{1}$ (a) and axial stress (b) when damage has completely invaded the outer surface in the vicinity of the roughness defect $(\mathrm{S}-\mathrm{SiC})$.

allows us to observe what was shown by the highspeed camera: the three points of asymmetry, viz. a speed of about $150 \mathrm{~m} / \mathrm{s}$ near the flaw which initiates the failure, a speed of about $300 \mathrm{~m} / \mathrm{s}$ at the opposite side for $\mathrm{S}-\mathrm{SiC}$ specimen, projections closer to the centre from this opposite side, cracks which are bending over (Fig. 16). When comparing the computations using the two grades, no significant differences were observed. This is also confirmed when analysing the post-mortem micrographs (Fig. 7).

\section{Conclusion}

An experimental set-up was designed to study uniaxial compression of ceramics. The geometry 


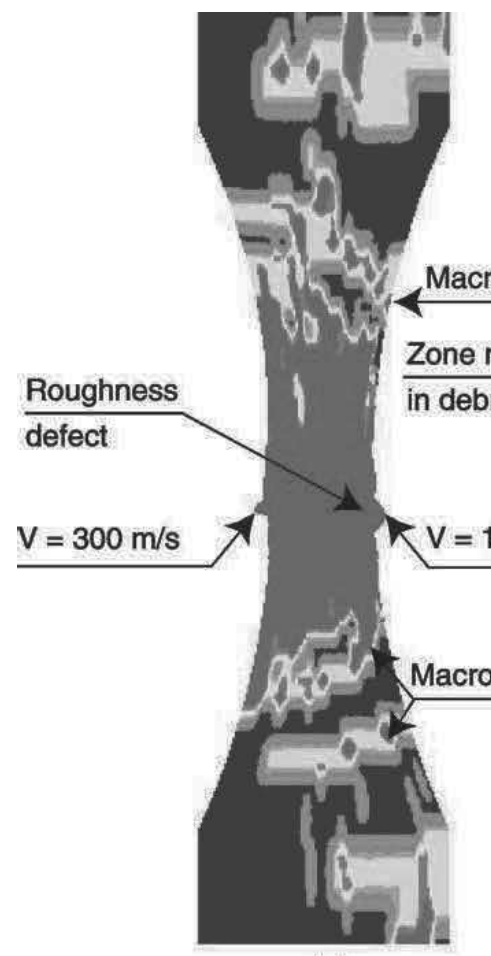

(a)

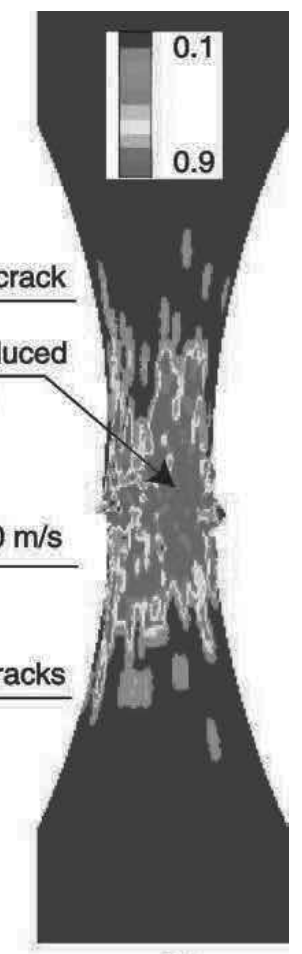

(b)
Fig. 16. Final damage contours associated with the first and third principal stress directions ( $D_{1}$ and $D_{3}$, respectively). These maps can be compared to the post-mortem observations (Fig. 7a) for an S-SiC sample.

leads to a compressive stress field almost uniaxial and homogeneous near the centre. Two SiC grades were examined. Photographs taken by using a high-speed camera showed that failure nucleated near the centre. As it was confirmed by the modelling, the non-axisymmetric damage observed on the photographs indicates that failure was initiated on the hourglass surface. A roughness defect may explain these observations. Moreover the fact that the failure strength levels and the Weibull moduli of the two $\mathrm{SiC}$ grades are almost identical in compression suggest that failure be probably caused by a roughness defect. The hypothesis that a single roughness defect may lead to failure was confirmed by a first modelling. The cracking pattern, the debris projections and the timing of cracking was also established with a second modelling. No damage (microcracking, microplasticity) was observed from a specimen loaded and unloaded before failure.
The experimental and numerical approaches developed herein should also be applicable to characterise the compressive strength of other brittle materials such as alumina ceramics or (high performance) concrete. In particular, the role of two defect populations has to be studied:

- the intrinsic flaw population induced by the fabrication (i.e., sintering for ceramics);

- the extrinsic flaw distribution caused by the preparation of the surface (e.g., grinding process).

The compressive strength is the result of the combination of both defect populations. The volume effect is mainly described by the intrinsic distribution and the scatter by the extrinsic defects for the $\mathrm{SiC}$ ceramics studied herein.

\section{Acknowledgements}

This work was funded by the Délégation Générale pour l'Armement (DGA). The authors wish to thank $\mathrm{R}$. Villatobas for performing parts of the experiments reported herein and L. Chevalier for his help during the TEM observations.

\section{References}

Bourne, N., Millet, J., Pickup, I., 1997. Delayed failure in shocked silicon carbide. J. Appl. Phys. 81, 6019-6023.

Cagnoux, J., Chartagnac, P., Hereil, P.-L., 1987. Lagrangian analysis: a modern tool of the dynamics of solids. Ann. Phys. Fr. 12, 514-541.

Cosculluela, A., 1992. Plasticité, endommagements et ruptures des alumines sous sollicitations dynamiques triaxiales: influence de la taille de grains. Ph.D. Dissertation, University of Bordeaux 1, France.

Cottenot, C., Beylat, L., Denoual, C., Lesdos, J., Senf, H., Strassburger, E., 1998. Experimental and numerical investigation of impact damage in different types of SiC. In: Van Niekerk, C. (Ed.), Proc. Ballistics Symposium. ADPA, pp. 49-56.

Davies, D.G.S., 1973. The statistical approach to engineering design in ceramics. Proc. Br. Ceram. Soc. 22, 429-452.

Denoual, C., Hild, F., 1998. On the characteristic scales involved in a fragmentation process. J. Phys. IV, 119-126. 
Denoual, C., Hild, F., 2000. A damage model for the dynamic fragmentation of brittle solids. Comput. Meth. Appl. Mech. Eng. 183, 247-258.

Dunlay, W.A., Tracy, C.A., Perrone, P.J., 1989. A proposed uniaxial compression test for high strength ceramics. US Army Mater. Technol. Lab. Rep. MTL TR 89-89.

Feng, R., Raiser, G.R., Gupta, Y.M., 1997. Material strength and inelastic deformation of silicon carbide under shock wave compression. J. Appl. Phys. 83, 79-86.

Forquin, P., 2000. Approches expérimentale et numérique du comportement du $\mathrm{SiC}$ lors d'une sollicitation quasi-statique uniaxiale. CTA report (2000 R 014).

Grady, D.E., Lipkin, J., 1980. Criteria for impulsive rock fracture. Geophys. Res. Lett. 7, 255-258.

Hibbitt, H.D., Karlsson, B.I., Sorensen, P., 1998. Abaqus 5.8 Version, User's Manual.

Kipp, E., Grady, D.E., 1990. In: Shock Compression and Release in High-strength Ceramics. Elsevier Science Publishers B.V, pp. 377-380.

Lamaison, M., 1997. Contribution à la compréhension des phénomènes de rupture sous sollicitations dynamiques d'un diborure de titane et d'un tungstène. Ph.D. Dissertation, ENSAM of Bordeaux, France.

Lankford, J., 1977. Compressive strength and microplasticity in polycrystalline alumina. J. Mater. Sci. 12, 791-796.

Lankford, J., 1981. Mechanisms responsible for strain-ratedependent compressive strength in ceramic materials. Commun. Am. Ceram. Soc., C33-C34.
Lankford, J., 1982. Compressive strength, hardness, and indentation damage in ceramic materials. Technical report of the Southwest Research Institute, San Antonio, Texas, USA.

Lankford, J., 1991. The compressive strength of strong ceramics: microplasticity versus microfracture. J. Hard Mater. 2 (1-2), 55-77.

Lemaitre, J., 1992. A Course on Damage Mechanics. Springer, Berlin, Germany;

See also Lemaitre, J., Chaboche, J.-L. Mechanics of Solid Materials. Cambridge University Press, Cambridge, UK.

Malaise, F., 1999. Réponse d'une céramique à l'impact d'un barreau à grande vitesse $(1500 \mathrm{~m} / \mathrm{s})$. Croisement essais dynamiques - modélisation numérique. Ph.D. Dissertation, ENSAM of Bordeaux, France.

Pamshock, User's manual, 2000, Pam System International.

Riou, P., 1996. Contribution à l'étude de l'endommagement du Carbure de Silicium lors d'un impact de basse énergie: application aux blindages. Ph.D. Dissertation, Ecole Nationale Supérieure des Mines de Paris, France.

Spanier, J., Oldham, K.B., 1987. An Atlas of Functions. Springer Verlag, New York, USA

Tranchet, J.-Y., 1994. Comportement de deux matériaux fragiles polycristallins sous l'effet de la propagation d'une onde sphérique divergente. Ph.D. Dissertation, University of Bordeaux 1, France.

Yaziv, D., 1985. Shock Fracture and Recompaction of Ceramics. Ph.D. Dissertation, University of Dayton, USA. 